4 Antonio Martínez-Cob², Kosana Suvočarev ${ }^{1,2}$

$5{ }^{1}$ Corresponding author. E-mail: suvocarev@eead.csic.es. Phone: +34 976716075.

$6{ }^{2}$ Dept. Suelo y Agua, Estación Experimental Aula Dei, CSIC, Avda. Montañana

7 1005, 50059 Zaragoza, Spain.

\section{UNCERTAINTY DUE TO HYGROMETER SENSOR IN EDDY COVARIANCE LATENT HEAT FLUX MEASUREMENTS}

\title{
8
}

\section{ABSTRACT}

Half-hour latent heat flux (LE) was measured over an early-maturing peach orchard (Prunus persica L.) by two different hygrometers: 1) infrared gas analyzer (IRGA) (LiCOR, model Li-7500); and 2) ultraviolet hygrometer (Campbell, KH20). A good

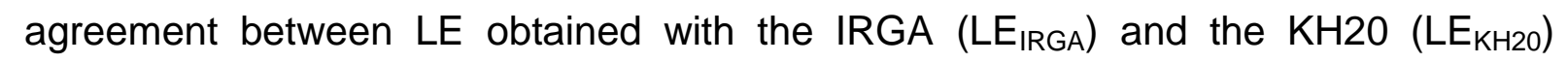
hygrometers was observed. During rainy periods, $L_{E_{\mathrm{IRGA}}}$ and $\mathrm{LE}_{\mathrm{KH} 20}$ were not reliable due to failure of the instruments caused by water drops standing over the sensors heads. Filtering out rainy periods improved the similarity between $L_{\mathrm{IRGA}_{\mathrm{RA}}}$ and $\mathrm{LE}_{\mathrm{KH} 20}$ : mean estimation error, $6.2 \mathrm{~W} \mathrm{~m}^{-2}$; root mean square error, $21.3 \mathrm{~W} \mathrm{~m}^{-2}$; and refined index of agreement, 0.919. Even though the IRGA hygrometer is generally recommended, when economic constraints exist, the $\mathrm{KH} 20$ hygrometer can be used with similar confidence.

\section{KEYWORDS}

4 Latent heat flux; Eddy covariance; Infrared gas analyzer; Krypton hygrometer; Error analysis 


\section{INTRODUCTION}

27 Improved management of irrigation water and several other hydrological issues 28 requires an accurate knowledge of actual evapotranspiration $\left(\mathrm{ET}_{\mathrm{a}}\right)$ of both crops 29 (optimal or stressed conditions) and natural vegetation. Several methods exist for $30 \mathrm{ET}_{\mathrm{a}}$ measurement and estimation (Hatfield et al., 2005). $\mathrm{ET}_{\mathrm{a}}$ represents the water 31 depth consumed by a plant surface (cropped or natural). This variable can also be represented in terms of an energy flux, the latent heat flux (LE), which represents the amount of energy per unit time required to evaporate a unit of water. The eddy covariance (EC) approach has been the preferred LE measurement method because of its accuracy and theoretical background. It entails fewer assumptions and is more direct than other micrometeorological methods, and the equipment can be easily moved from place to place in contrast to weighing lysimeters (Hatfield et al., 2005; Foken, 2008; Aubinet et al., 2012).

The EC method requires the high-frequency, fast-response measurements of the turbulent fluctuations of vertical wind speed and water vapor molar concentration. The former are measured by means of three-dimensional sonic anemometers. The latter are commonly measured by means of optical measuring methods based on Lambert-Beer's law (Foken, 2008). Hygrometers with ultraviolet (UV) and infrared (IR) radiation absorption are generally used. The appropriate operating range of vapor pressure is different for these two types of hygrometers. In addition, the calibration characteristics can change during the application time and, in this respect, the hygrometers working in the UV range are more affected than those in the IR range (Foken, 2008). Several commercial UV and IR hygrometers are available. There have been several previous valuable sensor intercomparison experiments for characterizing the uncertainties of turbulence measurements but most of them only 
51 considered the three-dimensional sonic anemometers (Mauder et al., 2006). Mauder

52 et al. $(2006 ; 2007)$ have compared the effect of the hygrometer in the uncertainty of 53 turbulence measurements. Mauder et al. $(2006,2007)$ evaluated the performance of 54 different EC systems, each system being the combination of a three-dimensional sonic anemometer and a hygrometer sensor. These authors reported that the deviations within the EC systems using an UV hygrometer were larger than those

57 within the EC systems using an IR hygrometer likely due to the sensitivity of the UV detector window to scaling effects and to corrosion of electrical contacts through condensing water in the sensor's enclosure, both effects causing shifts in the calibration curves. However, Mauder et al. (2006) did not test separately the 61 uncertainty due to the hygrometer to that due to the sonic anemometer. In addition, 62 the deviations between EC systems were in part (around 10 to $15 \%$ ) due to the different data analysis software packages. The results published by Mauder et al. (2007) were affected by technical problems due to application of one of the first serial numbers of IR hygrometer.

Currently most EC sites use open-path IR hygrometers, also known as infrared gas 67 analyzers (IRGA), that record high-frequency fluctuations of both $\mathrm{H}_{2} \mathrm{O}$ and $\mathrm{CO}_{2}$ concentrations (Munger et al., 2012). However, the cost of an IRGA hygrometer, such as the LI-7500 (Li-COR, Lincoln, Nebraska, USA), is about three times the cost of an UV hygrometer, such as the KH20 (Campbell Scientific, Logan, Utah, USA).

71 The goal of this paper was the comparison of LE obtained from two different 72 hygrometers (a LI-7500 and a $\mathrm{KH} 20$ ) combined with the same three-dimensional 73 sonic anemometer and using the same data analysis software package. In this way, 74 the effect of the hygrometer in the uncertainty of turbulence measurements was 75 evaluated without being affected by the sonic anemometer or the data analysis 
approach. The aim was answering the question whether the $\mathrm{KH} 20$ hygrometer can be as accurate as the IRGA hygrometer to get measured LE values.

\section{MATERIAL AND METHODS}

The measurements were carried out at a commercial early maturing peach (Prunus persica (L.) Batsch) orchard located in the stone-fruit orchard farm La Herradura (Caspe, Zaragoza, Spain). Measurements took place in 2010, from 27 Apr. to 5 May, 13 to 18 May, and 9 to 16 June. The experimental site was characterized by relatively high winds (long-term annual average wind speed at $2 \mathrm{~m}$ above ground is $3.1 \mathrm{~m} \mathrm{~s}^{-1}$ ) and semiarid climate (long-term annual precipitation and reference evapotranspiration, 315 and 1392 mm, respectively) (Martínez-Cob and Faci, 2010). The farm La Herradura was located next to a meander of the Ebro River, near to where the river forms a lake upstream of the Mequinenza dam (Fig. 1). The orchard topography was rough, with elevation ranging from 120 to $200 \mathrm{~m}$ above the mean sea level. Within the footprint of the micrometeorological tower the terrain is sloping down towards the point where the measurements were set, at $120 \mathrm{~m}$ above the mean sea level. Gradual rise occurs in the direction of the fetch limit, which is at 150 $\mathrm{m}$ above the mean sea level. Early maturing peaches represented about 51 ha (41 ha in the study zone) out of 227 ha total in the farm (Fig. 1). An EC station was set near the south east corner of the early maturing peach zone (41918'21" N latitude, 000'26" E) (Fig. 1). This zone included several cultivars with similar phenological characteristics. Row orientation was north to south and canopy height was $3.0 \mathrm{~m}$. The tree and row spacing were $3.0 \mathrm{~m}$ and $5.0 \mathrm{~m}$, respectively. 
100 The EC station consisted of a sonic anemometer (Campbell Scientific, CSAT3), a 101 krypton hygrometer (Campbell Scientific, KH20), an infrared gas analyzer (IRGA) (Li102 COR, Li-7500), a net radiometer (Kipp \& Zonen, NR-Lite), an air temperature and 103 relative humidity probe (Vaisala, HMP45C), four soil heat flux plates (Hukseflux, 104 HFP01) and two soil temperature sensors (Campbell Scientific, TCAV). A data logger 105 (Campbell Scientific, CR3000) was used to monitor these different sensors. All 106 instruments except the soil sensors were placed on the top of a tower, at $z=6.9 \mathrm{~m}$ 107 above the ground.

108 The sonic anemometer was placed pointing towards the northwest, about $308^{\circ}$ from 109 north clockwise, as this is the mid-point of the predominant wind direction range in 110 the middle Ebro River area (Martínez-Cob et al., 2010). The Krypton hygrometer was 111 installed at about $0.15 \mathrm{~m}$ horizontal distance, downwind the CSAT3. Similarly, the 112 IRGA hygrometer was installed about $0.10 \mathrm{~m}$ horizontal distance downwind the 113 Krypton hygrometer, i.e. about $0.25 \mathrm{~m}$ downwind the CSAT3. Both hygrometers were 114 slightly shifted behind downwind the CSAT3; the IRGA hygrometer was slightly tilted 115 as recommended by manufacturer. The Krypton hygrometer was calibrated at the 116 factory and IRGA hygrometer was calibrated in laboratory using a dew point 117 generator (LI-610, LiCor Inc.). Both calibration procedures took place during spring 118 2010. The net radiometers were placed oriented towards south. Soil heat flux plates 119 were buried at $0.1 \mathrm{~m}$ depth, two in between rows and the other two in the row. Each 120 soil temperature probe had four thermocouples (chromel-constantan), buried into 121 pairs at $0.03 \mathrm{~m}$ and $0.06 \mathrm{~m}$ depth above each soil heat flux plate.

122 Sensors were monitored at a $10 \mathrm{~Hz}$ frequency. The $10 \mathrm{~Hz}$ raw data included wind 123 speed at the $x$ and $y$ horizontal axes and at the $z$ vertical axis, sonic temperature, $124 \mathrm{CO}_{2}$ concentration, $\mathrm{H}_{2} \mathrm{O}$ concentration recorded from the krypton $\left(\rho_{h_{\_} K \mathrm{~K} 20}\right)$ and the 
125 IRGA ( $\left.\rho_{\mathrm{h} \_I R G A}\right)$ hygrometers, air temperature and vapor pressure recorded from the 126 Vaisala probe, net radiation, soil heat flux at $0.1 \mathrm{~m}$ soil depth (four sites) and soil 127 temperature at 0.03-0.6 m depth (two sites). The datalogger processed online the 128 raw data to get 30-min averages of turbulent fluxes following the basics of the EC 129 method (Foken, 2008; Aubinet et al. 2012; Campbell Scientific, 2013): a) latent heat 130 flux from the covariance of the fluctuations of vertical wind speed and $\rho_{\mathrm{h} \_ \text {KH20 }}$ 131 (LE $\left.E_{K H 20}\right)$; b) latent heat flux from the covariance of the fluctuations of vertical wind 132 speed and $\rho_{\mathrm{h} \_I R G A}\left(L_{I R G A}\right)$; c) sensible heat flux $(H)$ from the covariance of the 133 fluctuations of vertical wind speed and sonic temperature; and d) net photosynthesis 134 from the covariance of the fluctuations of vertical wind speed and $\mathrm{CO}_{2}$ concentration. 135 Values of $L_{E_{K H 20}}$ and $L E_{I R G A}$ were corrected online using the Webb, Pearman and 136 Leuning (WPL) correction; additionally, the values of $L_{\mathrm{KH} 20}$ were corrected online to 137 take into account the presence of oxygen which also absorbs the UV radiation 138 emitted by the krypton hygrometer (Campbell Scientific, 2013). Likewise, 30-min 139 averages of air temperature, vapor pressure, net radiation, horizontal wind speed and 140 compass wind direction, soil heat flux at $0.1 \mathrm{~m}$ depth (four sites) and soil temperature 141 at 0.03-0.06 $\mathrm{m}$ depth (two sites) were computed online and stored for further 142 analysis. The EC station also included a rain gauge (Campbell, ARG100) to record 143 30-min total precipitation. The 30-min average soil heat flux values were corrected 144 offline as described by Allen et al. (1996) using the average soil temperature values 145 to get soil heat flux at the soil surface at each site; later, the four 30-min soil heat flux 146 values obtained were averaged to get a single value.

147 For each half hour period, the cumulative normalized contribution to fluxes (CNF, \%) 148 was estimated following Burba y Anderson (2010) as follows:

$$
C N F=\exp \left[\frac{-U(z-d)}{u^{*} x_{L} k}\right]
$$


150 Where $U$ is average wind speed $\left(\mathrm{m} \mathrm{s}^{-1}\right), \mathrm{u}^{*}$ is friction velocity $\left(\mathrm{m} \mathrm{s}^{-1}\right) ; \mathrm{z}$ is 151 measurement height (6.9 $\mathrm{m}$ in this case); $\mathrm{d}$ is zero plane displacement $(\mathrm{m}), \mathrm{k}$ is the 152 von Kárman's constant (0.4) and $\mathrm{x}_{\mathrm{L}}$ is the upwind fetch distance $(\mathrm{m})$; $\mathrm{d}$ was estimated 153 as $d=2 / 3 h_{c}$ (Burba and Anderson, 2010), where $h_{c}$ is the crop height ( $3 \mathrm{~m}$ in this 154 case). Eq. (1) was used to determine which $x_{L}$ distance provided CNF $\geq 80 \%$ for 155 most half-hour periods inside the appropriate range of wind directions.

$156 \mathrm{LE}_{\mathrm{KH} 20}$ and $\mathrm{LE}_{\mathrm{IRGA}}$ were compared by simple regression analysis and several error 157 statistics were computed following Willmott et al. (2012): mean estimation error 158 (MEE), root mean square error (RMSE), and refined index of agreement $\left(\mathrm{d}_{\mathrm{r}}\right)$. No 159 comparison was performed between $\rho_{\mathrm{h}_{\_} \mathrm{KH} 20}$ and $\rho_{\mathrm{h}_{\_} \mathrm{RRGA}}$ as the $\mathrm{KH} 20$ manufacturer 160 claims that this hygrometer is not suitable to provide measurements of absolute $\mathrm{H}_{2} \mathrm{O}$ 161 concentrations, but $\mathrm{H}_{2} \mathrm{O}$ concentration fluctuations and thus LE when used with a sonic anemometer (Campbell Scientific, 2010).

\section{RESULTS AND DISCUSSION}

165 Rainfall was irregularly distributed as it is typical in semiarid climates. A total of 34.6 166 $\mathrm{mm}$ were recorded in the study period, but $92.5 \%$ was recorded in three rainfall events: 2 May (21:00 Universal Time Coordinated, UTC) to 3 May (22:30 UTC), 9 June (5:00 UTC) to 10 June (2:00 UTC), and 12 June (14:00 to 16:00 UTC).

169 Table 1 lists the percentage of half-hour periods for which the CNF (computed from 170 Eq. 1) was above $80 \%$ as a function of $x_{L}$. At first glance, Table 1 indicates that the 171 appropriate fetch distance could be $500 \mathrm{~m}$. However, the irregular shape of the

172 orchard, and the relatively rough topography precluded such large fetch distance for 173 most compass wind directions. It is also necessary to take into account that Eq. (1) 174 computes CNF for neutral atmospheric conditions but that a shorter fetch distance is 
175 required for unstable atmospheric conditions (Burba and Anderson, 2010). Thus a

176 conservative compromise between these different criteria led us to select an upwind

177 fetch distance of $425 \mathrm{~m}$ as appropriate for this study. For $\mathrm{XL}=425 \mathrm{~m}$, about $60 \%$ of

178 the half-hour periods had a CNF above $80 \%$ (Table 1).

179 Once an upwind fetch distance was selected, a visual inspection of Fig. 1 selected a 180 compass wind direction range of 240 to $330^{\circ}$ assuring that the selected fetch 181 distance of $425 \mathrm{~m}$ was available. A total of 874 half-hour periods were recorded 182 during the three measurement periods. However, only a total of 438 half-hour periods 183 (about $50 \%$ ) were retained for further analysis. Even though Eq. (1) only applies for 184 neutral atmospheric conditions and unstable atmospheric conditions have lower fetch 185 requirements, selecting a shorter fetch distance (i.e. less than $425 \mathrm{~m}$ ) for the rest of 186 compass wind directions was not possible as the EC station was located in the 187 southeast corner of the orchard (Fig. 1). This stresses the difficulties for practical 188 applications of the EC method that can be found in areas of relatively rough 189 topography due to the important limitations imposed by the large fetch requirements 190 and the varying compass wind direction along the season. Nevertheless, that limited 191 data set still was large enough for the main goal of this study.

192 Fig. 2 displays the half-hour values of $L_{K_{H} 20}$ and $L E_{I R G A}$ retained for analysis as a 193 function of time. In general terms, there was a good agreement between both 194 datasets of LE. The equation for the simple linear regression of $L_{\text {IRGA }}$ (dependent 195 variable $y$ ) on $L_{K_{H} 20}$ (independent variable $x$ ) was $y=23.1+0.899 x$ with a 196 coefficient of determination $\mathrm{R}^{2}=0.772$. The MEE and RMSE were 14.3 and $43.5 \mathrm{~W}$ $197 \mathrm{~m}^{-2}$, respectively, while the $d_{r}$ was 0.856 . It was particularly noticeable the agreement 198 for the period 13 to 18 May. During this period, the meteorological conditions (high 199 wind speed, high net radiation, absence of precipitation and dryness) likely led to 
200 better development of atmospheric turbulence and thus high-size eddies. Thus, it is 201 likely that the sonic anemometer and both hygrometers sampled at a higher extent 202 the same eddies. The absence of precipitation in this period precluded the presence 203 of water drops standing over the hygrometer heads disturbing the corresponding 204 measurements. For the other two periods, 27 Apr. to 5 May and 9 to 16 June, the 205 agreement between $L_{E_{K H} 20}$ and $L E_{I R G A}$ was somewhat worse. The lack of agreement 206 was particularly noticeable during the periods for which rainfall events were recorded, 2072 to 3 May, 9 to 10 June, and 12 June. During these rainy periods, the LE $E_{\text {IRGA }}$ values 208 were much higher than the $\mathrm{LE}_{\mathrm{KH} 20}$ values, which were close to 0 (Fig. 2). The 209 presence of water drops standing over the head of the KH2O and IRGA disturbed the 210 corresponding readings of these sensors. According to Foken (2008), UV 211 hygrometers (as the $\mathrm{KH} 20$ ) are more suited for measuring low absolute humidity and 212 their optical windows are treated with hygroscopic material which also may affect the 213 readings of these type of sensors when humidity is high as it occurs during and just 214 after rainfall events. In addition, the $\mathrm{KH} 20$ sensor head was surrounded by a short 215 flange that could retain a shallow water layer standing over the head during rainfall 216 events, while this flange was absent around the IRGA sensor head. Also, data from 217 open path IRGAs become erroneous when the turbidity of the window exceeds a 218 given threshold, usually caused by accruing water (Haslwanter et al., 2009).

219 Therefore, a second filtering step was performed to remove rainy half-hour periods 220 from further analysis. After this, 387 half-hour periods were kept for a further 221 comparison of $L E_{K H 20}$ and $L E_{I R G A}$. Fig. 3 shows the simple linear regression of $L E_{\mathbb{R G A}}$ 222 (dependent variable $y$ ) on $\mathrm{LE}_{\mathrm{KH} 20}$ (independent variable $\mathrm{x}$ ) for these 387 half-hour 223 periods. There was a close agreement between both datasets even though there was 224 still some discrepancy for a few instances (no clear reason for it could be found). The 
225 regression slope was not significantly different than 1 although the intercept was 226 significantly different than $0(\alpha=0.05)$. The MEE and RMSE were 6.2 and $21.3 \mathrm{~W} \mathrm{~m}^{-}$

$222^{2}$, and the $d_{r}$ was 0.919 . These statistics indicate that the agreement between LE $E_{K H 20}$ 228 and LE $E_{\text {IRGA }}$ in this work was better than that reported by Mauder et al. $(2006,2007)$. 229 Namely, IRGA hygrometer used by Mauder et al. (2007) was one of the first serial 230 numbers of the LI-7500 IRGA sensor type and had some technical problems. The 231 results by Mauder et al. (2006) are based on comparison between the instruments 232 mounted at different micrometeorological towers. Consequently, they reported higher 233 RMSE values of 28.5 and $37.7 \mathrm{~W} \mathrm{~m}^{-2}$, respectively, and higher intercept values and 234 regression slopes of 0.98 and 1.17. One should take into account that the differences 235 between $L_{E_{K H} 20}$ and $L E_{I R G A}$ reported by Mauder et al. $(2006,2007)$ included not only 236 the uncertainty due to the hygrometer sensor but also those due to the sonic 237 anemometer (they compared combinations of sonic anemometers and hygrometers) 238 and post-processing software packages. In general, there is a tendency for the $239 \mathrm{LE}_{\mathrm{IRGA}}$ values to be slightly higher than the $\mathrm{LE}_{\mathrm{KH} 20}$ values.

240 Thus the energy balance closure for LE $E_{I R G A}$ was slightly better than that for $L_{K H 20}$ 241 (data not shown). It was in both cases within reported values for different canopies 242 according to Wilson et al., (2002) and Stoy et al.(2013).

243 The results found in this paper suggest that both types of hygrometers can provide 244 similar results with similar uncertainty as long as 'optimal' measurement conditions 245 occur. The slightly better energy balance closure found for $\mathrm{LE}_{\mathrm{IRGA}}$ is not enough to 246 conclude that the IRGA hygrometer clearly provided better measured LE values. 247 Thus when economic constraints exist, the $\mathrm{KH} 20$ hygrometer can be also used with 248 confidence. In terms of LE, there is not a clear superiority of the IRGA hygrometer. 
249 The main advantage of using this hygrometer would be for those studies for which

$250 \mathrm{CO}_{2}$ concentrations are also required.

\section{CONCLUSIONS}

253 The LE values obtained with two different types of hygrometer, IRGA and KH20, 254 were quite similar in general terms. The largest differences were found during rainy 255 periods. When filtering out those rainy periods, the similarity between $\mathrm{LE}_{\mathrm{IRGA}}$ and 256 LE $_{\mathrm{KH} 20}$ was high. The statistics MEE, RMSE and $d_{r}$ were $6.2 \mathrm{~W} \mathrm{~m}^{-2}, 21.3 \mathrm{~W} \mathrm{~m}^{-2}$, and 257 0.919, respectively. Therefore, whenever economic constraints exist, the KH20 can 258 be used with confidence.

259

\section{REFERENCES}

261 Allen, R.G., Pruitt, W.O., Businger, J.A., Fritschen, L.J., Jensen, M.E., Quinn, F.H., 262 1996. Evaporation and transpiration. 125-252. In: Heggen, R.J., Wootton, T.P., 263 Cecilio, C.B., Fowler, L.C., Hui, S.L. (Eds.), Hydrology Handbook. $2^{\text {nd }}$ ed. American 264 Society of Civil Engineers, New York, USA.

265 Aubinet, M., Vesala, T., Papale, D. (eds). 2012. Eddy Covariance: a Practical Guide 266 to Measurement and Data Analysis. Springer-Verlag, Berlin, Germany. 438 pp.

267 Burba, G., Anderson, D. 2010. A Brief Practical Guide to Eddy Covariance Flux 268 Measurements. Version 1.01. Li-COR Biosciences, Lincoln, Nebraska, USA.

269 Campbell Scientific. 2010. KH20 Krypton Hygrometer User Manual. Issued 23 March 270 2010. Campbell Sci., Ltd. Logan, USA. http://www.campbellsci.co.uk/manuals.

271 Campbell Scientific. 2013. Open Path Eddy Covariance (OPEC). Issued 7 May 2013.

272 Campbell Sci., Ltd. Logan, USA. http://www.campbellsci.co.uk/manuals.

273 Foken, T. 2008. Micrometeorology. Springer-Verlag, Berlin, Germany. 306 pp. 
274 Girona, J., Marsal, J., López, G. 2006. Establishment of Stem Water Potential 275 Thresholds for the Response of 'O'Henry' Peach Fruit Growth to Water Stress 276 During Stage III of Fruit Development. Acta Hort. 713, 197-202.

277 Haslwanter, A., Hammerle, A., Wohlfahrt, G., 2009. Open- vs. closed-path eddy 278 covariance measurements of the net ecosystem carbon dioxide and water vapour 279 exchange: a long-term perspective. Agric. For. Meteorol. 149, 291-302.

280 Hatfield, J.L., Baker, J.M., Viney, M.K. 2005. Micrometeorology in Agricultural 281 Systems. Agronomy Monograph No. 47. American Society of Agronomy, Crop 282 Science Society of America, Soil Science Society of America, Madison, WI, USA. $283584 \mathrm{pp}$.

284 Martínez-Cob, A., Faci, J.M. 2010. Evapotranspiration of a hedge-pruned olive 285 orchard in a semiarid area of NE Spain. Agric. Water Manage. 97, 410-418.

286 Martínez-Cob, A., Zapata, N., Sánchez, I., 2010. Viento y Riego: la variabilidad del 287 viento en Aragón y su influencia en el riego por aspersión. Publication No. 2948. 288 Series Studies (Geography). Institución Fernando el Católico. Zaragoza, Spain. 200 289 pp. [in Spanish].

290 Mauder, M., Liebethal, C., Göckede, M., Leps, J.P., Beyrich, F., Foken, T. 2006. 291 Processing and Quality Control of Flux Data During LITFASS-2003. Bound. Layer 292 Meteorol. 121, 67-88.

293 Mauder, M., Oncley, S.P., Vogt, R., Weidinger, T., Ribeiro, L., Bernhofer, C., Foken, 294 T., Kohsiek, W., De Bruin, H.A.R., Liu, H. 2007. The Energy Balance Experiment 295 EBEX-2000. Part II: Intercomparison of Eddy-Covariance Sensors and Post-Field 296 Data Processing Methods. Bound. Layer Meteorol. 123, $29-54$.

297 Munger, J.W., Loescher, H.W., Luo, H. 2012. Measurement, tower, and site design 298 considerations. 21-58. In: Eddy Covariance, a practical guide to measurement and 
data analysis. Aubinet, M., Vesala, T., Papale, D. (eds.). Springer, Dordrecht, The

300 Netherlands.

301 Stoy, P.C., Mauder, M., Foken, T., Marcolla, B., Boegh, E., Ibrom, A., Arain, M.A., 302 Arneth, A., Aurela, M., Bernhofer, C., Cescatti, A., Dellwik, E., Duce, P., Gianelle, D., 303 van Gorsel, E., Kiely, G., Knohl, A., Margolis, H., McCaughey, H., Merbold, L., 304 Montagnani, L., Papale, D., Reichstein, M., Saunders, M., Serrano-Ortiz, P., 305 Sottocornola, M., Spano, D., Vaccari, F., Varlagin, A. 2013. A Data-driven Analysis of 306 Energy Balance Closure Across FLUXNET Research Sites: The Role of Landscape 307 Scale Heterogeneity. Agric. For. Meteorol. 171-172, 137-152.

308 Willmott, C.J., Robeson, S.M., Matsuura, K. 2012. A refined index of model 309 performance. Int. J. Climatol. 32 (13), 2088-2094.

310 Wilson, K., Goldstein, A., Falge, E., Aubinet, M., Baldocchi, D., Berbigier, P., 311 Bernhofer, C., Ceulemans, R., Dolman, H., Field, C., Grelle, A., Ibrom, A., Law, B.E., 312 Kowalski, A., Meyers, T., Moncrieff, J., Monson, R., Oechel, W., Tenhunen, J., 313 Valentini, R., Verma, S., 2002. Energy balance closure at FLUXNET sites. Agric. For. 314 Meteorol. 113, 223-243.

315 Zapata, N., Nerilli, E., Martínez-Cob, A., Chalghaf, I., Chalghaf, B., Fliman, D., 316 Playán, E., 2013. Limitations to adopting regulated deficit irrigation in stone fruit 317 orchards: a case study. Span. J. Agric. Res. 11, 529-546.

\section{ACKNOWLEDGMENTS}

319 Work funded by the project Consolider CSD2006 - 00067 (Ministerio de Ciencia e 320 Innovación, Spain). Thanks are due to the owners of the commercial orchard, to J.L. 321 Gracia (farm manager), and M. Izquierdo, J. Gaudó, J.M. Acín, E. Medina and C. 322 Merino for technical and field assistance. 


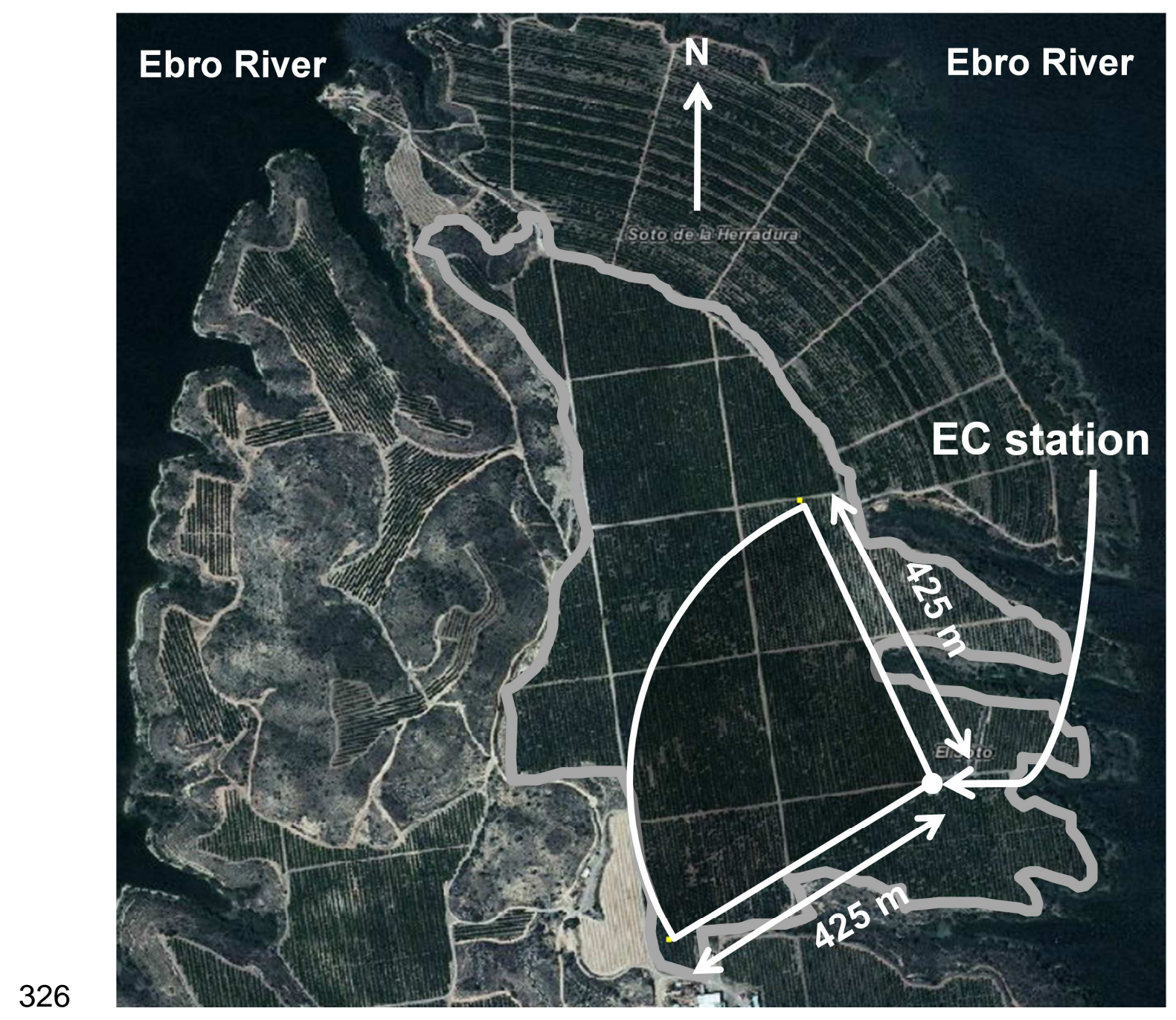

327 Fig. 1. Early-maturing peach orchard at the fruit-stone commercial orchard La 328 Herradura (Caspe, Zaragoza, Spain). The location of the eddy covariance and the 329 area within which fetch requirements are accomplished is also displayed. 

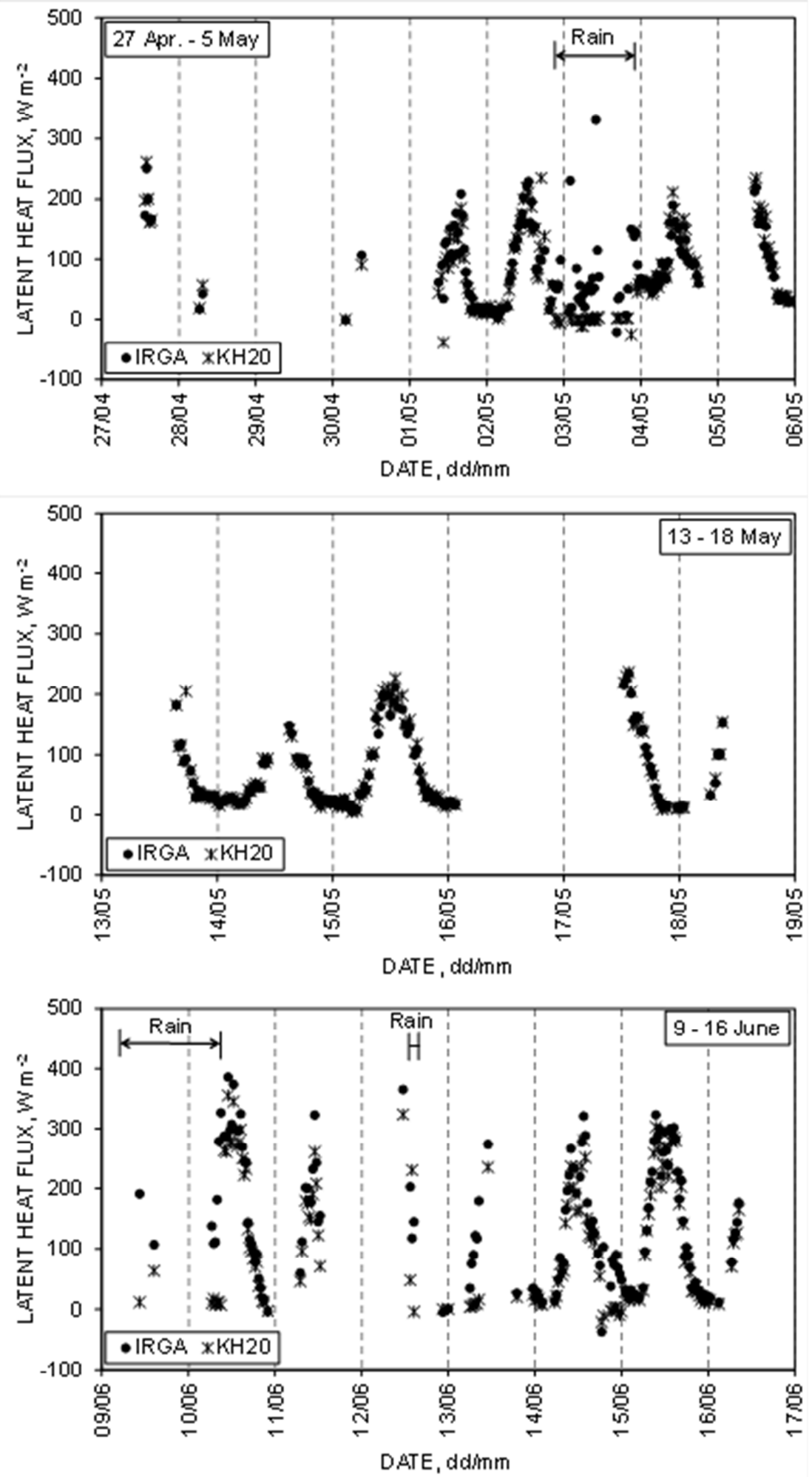

332 Fig. 2. Half-hour values of latent heat flux measured with a Campbell KH20 333 hygrometer $\left(\mathrm{LE}_{\mathrm{KH} 20}\right)$ and a Li-Cor Li-7500 infrared gas analyzer (LE $\mathrm{IRGA}_{\text {). The }}$ 334 duration of the main rainfall events is also displayed. 


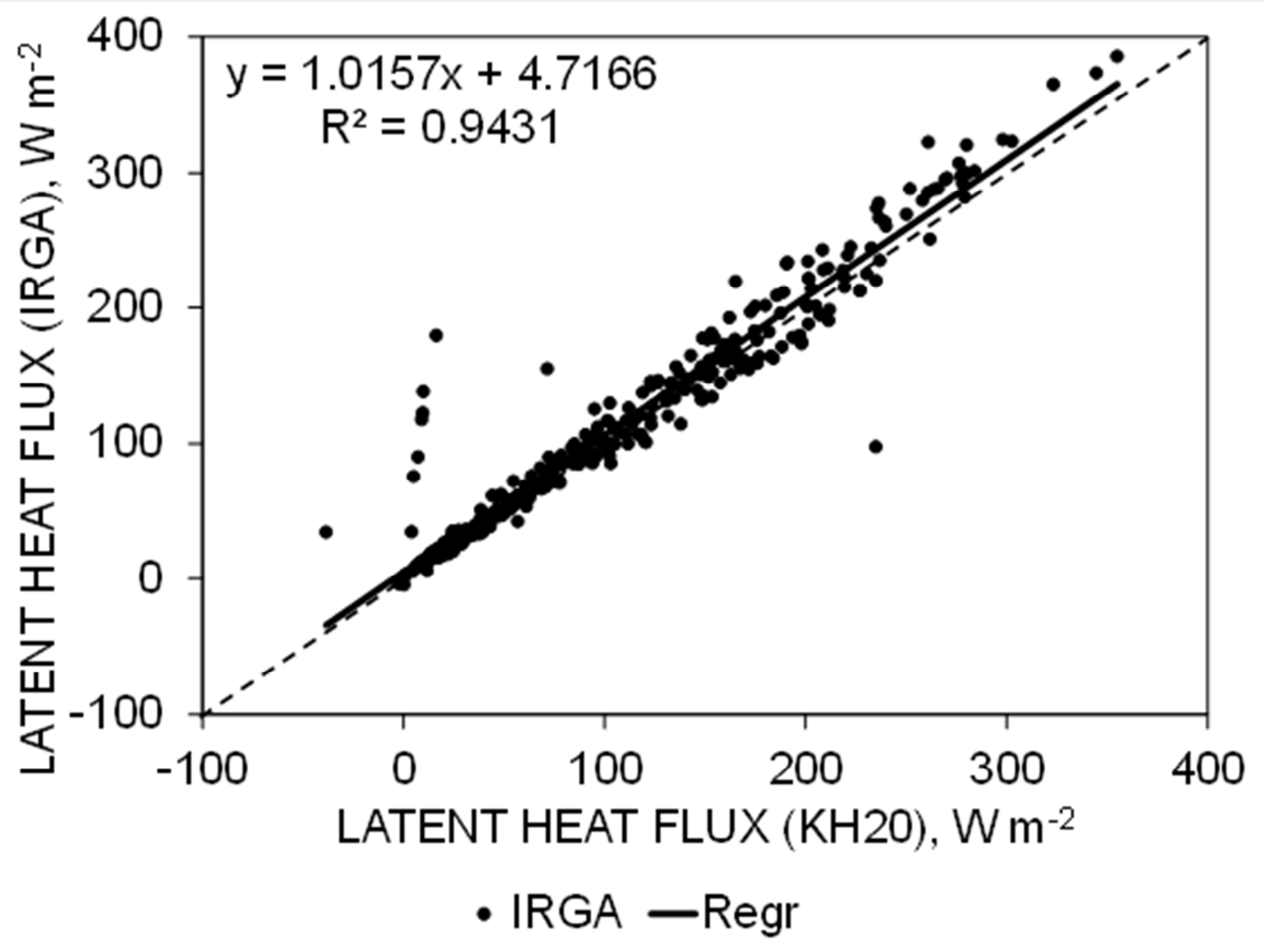

337 Fig. 3. Half-hour values of latent heat flux measured with a Campbell KH2O 338 hygrometer $\left(\mathrm{LE}_{\mathrm{KH} 2 \mathrm{O}}\right)$ versus those measured with a Li-Cor Li-7500 infrared gas 339 analyzer ( $\left.L E_{\mathbb{I R G A}}\right)$ after excluding rainy half-hour periods from those displayed on Fig. 3402. 
344 Table 1. Percentage of half-hour periods $\left(\mathrm{N}_{\mathrm{CNF80}}\right)$ for which the cumulative 345 normalized contribution to fluxes was above $80 \%$ as a function of upwind fetch 346 distance $\left(\mathrm{x}_{\mathrm{L}}\right)$.

\begin{tabular}{|l|l|l|l|l|l|l|l|}
\hline $\mathrm{X}_{\mathrm{L}}, \mathrm{m}$ & 350 & 375 & 400 & 425 & 450 & 475 & 500 \\
\hline $\mathrm{N}_{\mathrm{CNF80}}, \%$ & 19.4 & 34.6 & 51.9 & 59.6 & 64.8 & 69.8 & 73.9 \\
\hline
\end{tabular}

348 